\title{
Northern Hemisphere patterns of phase coherence between solar/geomagnetic activity and NCEP/NCAR and ERA40 near-surface air temperature in period 7-8 years oscillatory modes
}

\author{
M. Paluš ${ }^{1}$ and D. Novotná ${ }^{2}$ \\ ${ }^{1}$ Institute of Computer Science, Academy of Sciences of the Czech Republic, Pod vodárenskou věží 2, 18207 Prague 8, \\ Czech Republic \\ ${ }^{2}$ Institute of Atmospheric Physics, Academy of Sciences of the Czech Republic, Boční II/1401, 14131 Prague 4, \\ Czech Republic
}

Received: 8 November 2010 - Revised: 12 March 2011 - Accepted: 14 March 2011 - Published: 1 April 2011

\begin{abstract}
Beginning from the 1950's, Paluš and Novotná (2009) observed statistically significant phase coherence among oscillatory modes with the period of approximately 7-8 years detected in monthly time series of sunspot numbers, geomagnetic activity aa index, North Atlantic Oscillation (NAO) index and near-surface air temperature from several mid-latitude European stations. Focusing on geographical distribution of the phenomenon we study Northern Hemisphere patterns of phase coherence between solar/geomagnetic activity and NCEP/NCAR and ERA40 nearsurface air temperature. Both the reanalysis datasets provide consistent patterns of areas with marked phase coupling between solar/geomagnetic activity and climate variability observed in continuous monthly data, independent of the season, however, confined to the temporal scale related to the oscillatory periods about $7-8$ years.
\end{abstract}

\section{Introduction}

A renewed interest in the field of Sun-climate relations, namely in detecting and understanding of climate responses to variable solar activity has led to a number of recently published interesting results (see Haigh, 2003, 2005, 2007; De Jager, 2005; Lean et al., 2005; Lockwood and Frohlich, 2007; Tinsley, 2008; Lockwood, 2009 and references therein). There is empirical evidence that the response to solar signal is not homogenously distributed over the at-

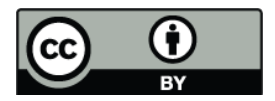

Correspondence to: M. Paluš

(mp@cs.cas.cz) mosphere, but it shows latitudinal, longitudinal and altitudinal dependence. While there is a well-documented influence of the solar signal in the stratosphere, observations of the tropospheric responses to the solar variability are more ambiguous. Besides the geographical complexity, the dynamical coupling between the stratosphere and troposphere remains poorly understood (Rind et al., 2008; Simpson et al., 2009).

In this study we are interested in tropospheric responses to variable solar activity, in particular, in measurable influences of the solar variability observed in near-surface air temperature.

The strongest solar signal in the tropospheric temperature has been observed predominantly in middle latitudes (Haigh, 2003; Lu et al., 2007), eventually in the tropics and in the middle latitudes of both hemispheres (Gleisner and Thejll, 2003; Gleisner et al., 2005). Analogous latitudinal dependence-maximal response in the middle latitude near-surface air temperature was demonstrated by Lean and Rind (2008), while Camp and Tung (2007); Tung and Camp (2008) observed the strongest solar cycle response in higher latitudes.

With the aim to identify responses to solar forcing, relationships between the solar activity, or quantities closely related to the solar activity, and temperature data have been sought. Besides the well-known sunspot numbers, the aa index characterizing the geomagnetic activity provides the longest data set of solar proxies which goes back to 1868 (Mayaud, 1972). Significance of geomagnetic activity in investigation of climate response to solar signal is noticed in several works (Usoskin et al., 2005; De Jager and Usoskin, 2006; Lockwood and Frohlich, 2007).

Published by Copernicus Publications on behalf of the European Geosciences Union and the American Geophysical Union. 
A search for dynamical mechanisms of interacting complex processes underlying experimental data in many cases starts with an attempt to identify trends, oscillatory processes and/or other potentially deterministic signals in a noisy environment. Paluš and Novotná (1998, 2004, 2006, 2007, 2008) used the Enhanced Monte-Carlo Singular System Analysis (EMCSSA) in order to detect quasiperiodic phenomena in near-surface air temperature from a number of European stations, in the monthly North Atlantic Oscillation (NAO) index and, more recently, in the geomagnetic aa index and in the sunspot numbers. The North Atlantic Oscillation is a dominant pattern of atmospheric circulation variability in the extratropical Northern Hemisphere, accounting for about $60 \%$ of the total sea-level pressure variance. The NAO has a strong effect on European weather conditions, influencing meteorological variables including temperature (Hurrell et al., 2001a,b). A number of oscillatory modes, some of them with quite similar periods (Paluš and Novotná, 2007, 2008), have been identified in both the solar/geomagnetic data and climate data, the latter represented by near-surface air temperatures from European stations and the NAO index. The existence of oscillatory modes of common frequencies allows for an application of phase-synchronization analysis (Pikovsky et al., 2001; Paluš and Novotná, 2006; Paluš et al., 2000, 2007) in order to detect possible interactions in the studied data. Not surprisingly, 11 years cycles in the sunspot data and the geomagnetic aa index have been found phase-coherent. There was, however, no phase relations found in the 11 years cycle between the solar/geomagnetic data and the climate data, neither the 11 years cycle have been found significantly present in the near-surface air temperature records in the mid-latitude European stations in the EMCSSA tests. Possible harmonics, i.e. cycles with period 5.5 years have been identified in these temperature records, however, they are not locked with the solar 11 years cycle (Paluš and Novotná, 2009). These results are in agreement with those of Moore et al. (2006) who found no consistent phase relationship between the 11 years sunspot cycles and the sea ice extent or the spring ice break-up in seas and ports, sea surface temperatures, sea level pressure, and various long meteorological records from cities in Europe.

On the other hand, the EMCSSA analysis statistically confirmed existence of oscillatory modes with the period 78 years in both climate (NAO index, near-surface air temperature from mid-latitude European stations) and solar/geomagnetic data. Instantaneous phases of the modes underwent synchronization analysis and their statistically significant phase coherence, beginning from 1950's, has been observed. Thus Paluš and Novotná (2009) were able to present the statistical evidence for a coupling between solar/geomagnetic activity and climate variability, obtained from continuous monthly data, independent of the season, however, confined to the temporal scale related to oscillatory periods about $7-$ 8 years.
In our previous analyses (Paluš and Novotná, 1998, 2004, 2006, 2007, 2009) the long-term near-surface temperature records from European stations were used. In this paper we study Northern Hemisphere geographical patterns of phase coherence between solar/geomagnetic activity and near-surface air temperature from NCEP/NCAR and ERA40 reanalysis data, considering the period 7-8 years oscillatory modes. Thus we map a relative strength of the solar/geomagnetic influence on a part of temperature variability over the Northern Hemisphere and compare the results with the pattern of coherence between the NAO index and NCEP/NCAR and ERA40 near-surface temperatures. For better comparability of results of the previous and the present studies the identical characteristics of solar/geomagnetic activity (sunspots numbers, aa index) were used.

\section{Methods}

The phase synchronization analysis (Pikovsky et al., 2001; Paluš and Novotná, 2006; Paluš et al., 2000, 2007) is a useful tool for discovering weak dependence in noisy, nonstationary and relatively short data from oscillatory processes. It has many successful applications in physiology (Schäfer et al., 1998) and other sciences (Pikovsky et al., 2001). In analysis of climate related data, Maraun and Kurths (2005) have found epochs of phase coherence between the El Niño-Southern Oscillation and the Indian monsoon. Tatli (2007) presents phase synchronization between the North Sea-Caspian pattern index and near-surface air temperature over large territories of the extratropical Northern Hemisphere. Considering a system whose evolution is dominated by a (quasi-)oscillatory dynamics, the state of such a system can be described by its instantaneous phase $\phi$ (Pikovsky et al., 2001). For a measured time series, the phase $\phi$ can be obtained using the analytic signal concept of Gabor (1946). For an arbitrary time series $s(t)$ the analytic signal $\psi(t)$ is a complex function of time defined as

$\psi(t)=s(t)+i \hat{s}(t)=A(t) e^{i \phi(t)}$.

The instantaneous phase $\phi(t)$ of the signal $s(t)$ is then

$\phi(t)=\arctan \frac{\hat{s}(t)}{s(t)}$.

There are several ways how to determine the imaginary part $\hat{s}(t)$ of the analytic signal $\psi(t)$. In the standard approach of Gabor (1946), $\hat{s}(t)$ is given by the (discrete) Hilbert transform of $s(t)$ (Rosenblum et al., 1996; Paluš, 1997; Pikovsky et al., 2001). When this procedure is applied to a broadband signal, a filtering procedure is required before computing the Hilbert transform.

The approach used in this study is based on the wavelet transform (Torrence and Compo, 1998). Applying a continuous complex wavelet transform (CCWT thereafter) directly to time series $s(t)$, the complex coefficients related to the 
scale (frequency) of the studied cycles (here the period of 96 months) can directly be used in Eq. (2) for the estimation of the phase $\phi(t)$. The CCWT provides both the band-pass filtering of the signal and the phase estimation. In a similar context, Moore et al. (2006) use the wavelet extracted phases to search for relations between the sunspot cycle and various meteorological records. Using the same type of phases, Mokhov and Smirnov (2006) demonstrated that the El NiñoSouthern Oscillation drives the North Atlantic Oscillation.

Both the filtering and the phase estimation is also given as an output of singular system analysis. Paluš and Novotná (2007) had used the EMCSSA for the detection of the oscillatory modes in the analyzed data. Once the existence of a particular mode is confirmed in the EMCSSA test, for the phase synchronization analysis it is suitable to extract the instantaneous phase of the detected mode by using the CCWT which gives the instantaneous phases correctly localized in time (Paluš and Novotná, 2006; Paluš et al., 2005).

In the classical case of periodic self-sustained oscillators, existence of their coupling (dependence) can lead to phase synchronization, defined as a phase locking, i.e., the phase difference $\Delta \phi(t)=\phi_{1}(t)-\phi_{2}(t)$ is constant. In the case of phase-synchronized chaotic or other complex and noisy systems, fluctuations of the phase difference typically occur. Therefore, the criterion for phase synchronization is that the absolute values of $\Delta \phi$ are bounded (Rosenblum et al., 1996). It is important to note that the instantaneous phases are not represented as cyclic functions in the interval $[0,2 \pi)$ or $[-\pi, \pi)$, but as monotonously increasing functions on the whole real line. Then also the instantaneous phase difference $\Delta \phi(t)$ is defined on the real line and is an unbounded (increasing or decreasing) function of time for asynchronous (independent) systems, while epochs of phase synchronization (or coherence) appear as plateaus in $\Delta \phi(t)$ vs. time plots. In order to prove that the phase synchronization (coherence) indeed exists in the analyzed data, it must be assessed in a quantitative way. A useful quantitative description of phase coupling is the mean phase coherence $\gamma$ defined as

$\gamma^{2}=\langle\cos (\Delta \phi(t))\rangle^{2}+\langle\sin (\Delta \phi(t))\rangle^{2}$

where \langle\rangle means the temporal average. The mean phase coherence (MPC) tends to zero for $\Delta \phi$ of asynchronous processes and to one for phase locked systems. Considering real, noisy data neither 0 nor 1 is reached. Therefore, possible presence of phase synchronization or phase coherence is assessed in a statistical test based on surrogate data (Paluš, 2007; Paluš and Novotná, 2006). The numerically generated surrogate data have the same frequency spectra (amplitudes of Fourier coefficients) as the original data, but their Fourier phases are randomized independently for each time series. Thus any dependence between the series, present in the original tested data, is removed in the surrogate data. However, the autocorrelations (serial correlations) of individual series are pre- served. A probability that $\gamma_{o}$, observed in the analyzed data, can occur by chance without any real dependence, is evaluated using a large number of surrogate data realizations. If the probability of a random occurrence of $\gamma \geq \gamma_{o}$ is smaller than, say, 5\%, we say that the statistical test is significant on the level $95 \%$, or with $p<0.05$. Such a result is usually considered as the statistical evidence for existence of phase synchronization in the studied pair of time series. Strictly speaking, however, such statistical testing provides the evidence for dependence of the phases, but not necessarily for the specific physical mechanism of phase synchronization. Therefore we will use the broader term "phase coherence" instead of the more specific "phase synchronization".

\section{Data}

For comparison with the previous study (Paluš and Novotná, 2009), we briefly demonstrate some results obtained using monthly mean values of the near-surface air temperature from these stations: Prague-Klementinum (longitude $14^{\circ} 25^{\prime} \mathrm{E}$, latitude $\left.50^{\circ} 05^{\prime} \mathrm{N}\right)$, Bamberg $\left(10^{\circ} 53^{\prime} \mathrm{E}, 49^{\circ} 53^{\prime} \mathrm{N}\right)$, Basel $\left(07^{\circ} 35^{\prime} \mathrm{E}, 47^{\circ} 33^{\prime} \mathrm{N}\right)$, De Bilt $\left(05^{\circ} 11^{\prime} \mathrm{E}, 52^{\circ} 06^{\prime} \mathrm{N}\right)$, Potsdam $\left(13^{\circ} 04^{\prime} \mathrm{E}, 52^{\circ} 23^{\prime} \mathrm{N}\right)$, Vienna $\left(16^{\circ} 21^{\prime} \mathrm{E}, 48^{\circ} 14^{\prime} \mathrm{N}\right)$, and Zurich $\left(08^{\circ} 34^{\prime} \mathrm{E}, 47^{\circ} 23^{\prime} \mathrm{N}\right)$, from the period $1901-1999$ (Klein-Tank et al., 2002).

In this study we use monthly mean values of the nearsurface air temperature from the NCEP/NCAR (Kalnay et al., 1996) and ERA40 (Simmons and Gibson, 2000) reanalyses. We use the Northern Hemisphere data in the latitudes from 0 to $70^{\circ} \mathrm{N}$ in the grid of $2.5^{\circ} \times 2.5^{\circ}$ in the case of the ERA40 data and $1.875^{\circ} \times 1.9^{\circ}$ in the case of the NCEP/NCAR data. We evaluate the mean phase coherence for temporal segments of 512 months, starting in January 1958 and ending in August 2000 (see the thick solid line in Fig. 1b). As the only pre-processing of the data, the annual cycle was removed by subtracting the mean values for each month in the year.

The NAO index is defined as the normalized pressure difference between the Azores and Iceland. The monthly NAO index with its detailed description is available at http: //www.cru.uea.ac.uk/cru/data/. The aa index is a measure of the disturbance level of the Earths magnetic field based on magnetometer observations at two nearly antipodal stations: Hartland observatory in the UK and Canberra observatory in Australia. The aa-index was obtained from World Data Centre for Solar-Terrestrial Physics, Chilton, http://www. ukssdc.ac.uk/wdcc1/wdc_menu.html. The sunspot data was obtained from the SIDC-team, Royal Observatory of Belgium, Ringlaan 4, 1180 Brussels, Belgium, http://sidc.oma. be/DATA/monthssn.dat.

The time series with the monthly sampling obtained as the monthly mean values are used in all cases of the analysed data. 




Fig. 1. The instantaneous phase differences of pairs of the oscillatory modes obtained using CCWT with the central wavelet period 96 months from (a) the aa index and the near-surface air temperature from the 6 European stations listed in the Data section (all except of Prague-Klementinum) (thin solid lines); the aa index and the 70 years shifted Prague-Klementinum near-surface air temperature series (dashed line); (b) the aa index and the Prague-Klementinum $\left(14^{\circ} 25^{\prime} \mathrm{E}, 50^{\circ} 05^{\prime} \mathrm{N}\right)$ near-surface air temperature series (thin solid line); the aa index and the ERA40 near-surface air temperature closest to Prague grid point $\left(15^{\circ} 00^{\prime} \mathrm{E}, 50^{\circ} 00^{\prime} \mathrm{N}\right)$ (thick solid line); and the aa index and the ERA40 near-surface air temperature from a no-coherence area $\left(0^{\circ} 00^{\prime} \mathrm{E}, 25^{\circ} 00^{\prime} \mathrm{N}\right)($ dashed line).

\section{Results}

In order to remind the results of our previous study (Paluš and Novotná, 2009), in Fig. 1 we plot the instantaneous phase difference $\Delta \phi(t)$ between the aa index and several near-surface air temperature series, obtained using the central wavelet frequency related to the period of 96 months. The thin solid lines in Fig. 1a illustrate $\Delta \phi(t)$ between aa index and temperatures from Bamberg, Basel, De Bilt, Potsdam, Vienna and Zurich. The result for the Prague-Klementinum series is plotted in Fig. 1b using the thin solid line. In all cases $\Delta \phi(t)$ decreases at the beginning, however, a plateau occurs from 1950's. The phase coherence in the plateau was quantified using MPC and mutual information (Paluš, 1997) and tested using Fourier transform-based surrogate data with the results strongly supporting the existence of phase synchronization/coherence on the significance levels about $99.5 \%$ $(p<0.005)$ (Paluš and Novotná, 2009). For a visual demonstration of the difference between phase coherent and noncoherent modes, we plot $\Delta \phi(t)$ between the aa index and the Prague near-surface air temperature shifted by 70 years (dashed line in Fig. 1a). We can see that in this case $\Delta \phi(t)$ does not plateau but decreases also after 1950's with the same slope as before 1950's.

Now, in order to compare station data with the reanalysis gridded data, in Fig. 1b (thick solid line) we plot the instantaneous phase difference $\Delta \phi(t)$ between the aa index and the near-surface air temperature from the ERA40 grid point $15^{\circ} 00^{\prime} \mathrm{E}, 50^{\circ} 00^{\prime} \mathrm{N}$ (the closest ERA40 grid point to Prague). Apparently, $\Delta \phi(t)$ is confined to the plateau. On the other hand, the decreasing $\Delta \phi(t)$ (dashed line in Fig. 1b) was obtained from the ERA 40 grid point $0^{\circ} 00^{\prime} \mathrm{E}, 25^{\circ} 00^{\prime} \mathrm{N}$ which, as we will see below, belongs to one of the areas where no phase coherence between solar/geomagnetic activity and temperature variability was observed. These two $\Delta \phi(t)$ curves also demonstrate the temporal extent of all the following analyses - a segment of 512 months starting in January 1958, ending in August 2000.

Using the sunspot data with removed modes related to the 11 years cycle (Paluš and Novotná, 2008, 2009) and aa index and NAO index without any preprocessing, we have computed the instantaneous phase difference $\Delta \phi(t)$ between each of these three variables and near-surface air temperature data from each grid point of both the reanalysis sets. The instantaneous phases were obtained from the CCWT using the central wavelet frequency related to the period of 96 months. The behaviour of $\Delta \phi(t)$ has been quantified by mean phase coherence $\gamma$ according to Eq. (3). The MPC values are mapped, using color coding, in Fig. 2 for the ERA40 and in Fig. 3 for the NCEP/NCAR reanalysis data. The areas of strong phase coherence between the solar data (top panels) and geomagnetic aa index (middle panels) on one side and the temperature data on the other side seem to be more extended in the ERA40 data (Fig. 2) than in the NCEP/NCAR data (Fig. 3). Closer inspection and consideration of the different grid densities used, however, give arguments for a quite good consistency of the obtained results.

\section{Statistical evaluation}

The statistical significance of the observed mean phase coherence has been evaluated using the Fourier transformbased surrogate data. For each grid point 2000 surrogate realizations have been constructed. It is important to establish the statistical significance in each point separately, since the MPC values and their surrogate ranges depend not only on the actual coherence strength, but also on other properties of particular data. Thus it is impossible to establish a universal critical value for the statistical significance. On the other hand, the large number of statistical tests open the question of simultaneous statistical inference. For instance, testing all the 4176 ERA40 grid points, for the total outcome to be significant on the $95 \%$ level, a single point test should be significant on the level $99.999 \%$. Such overly conservative approach would diminish or destroy any significance. A more 


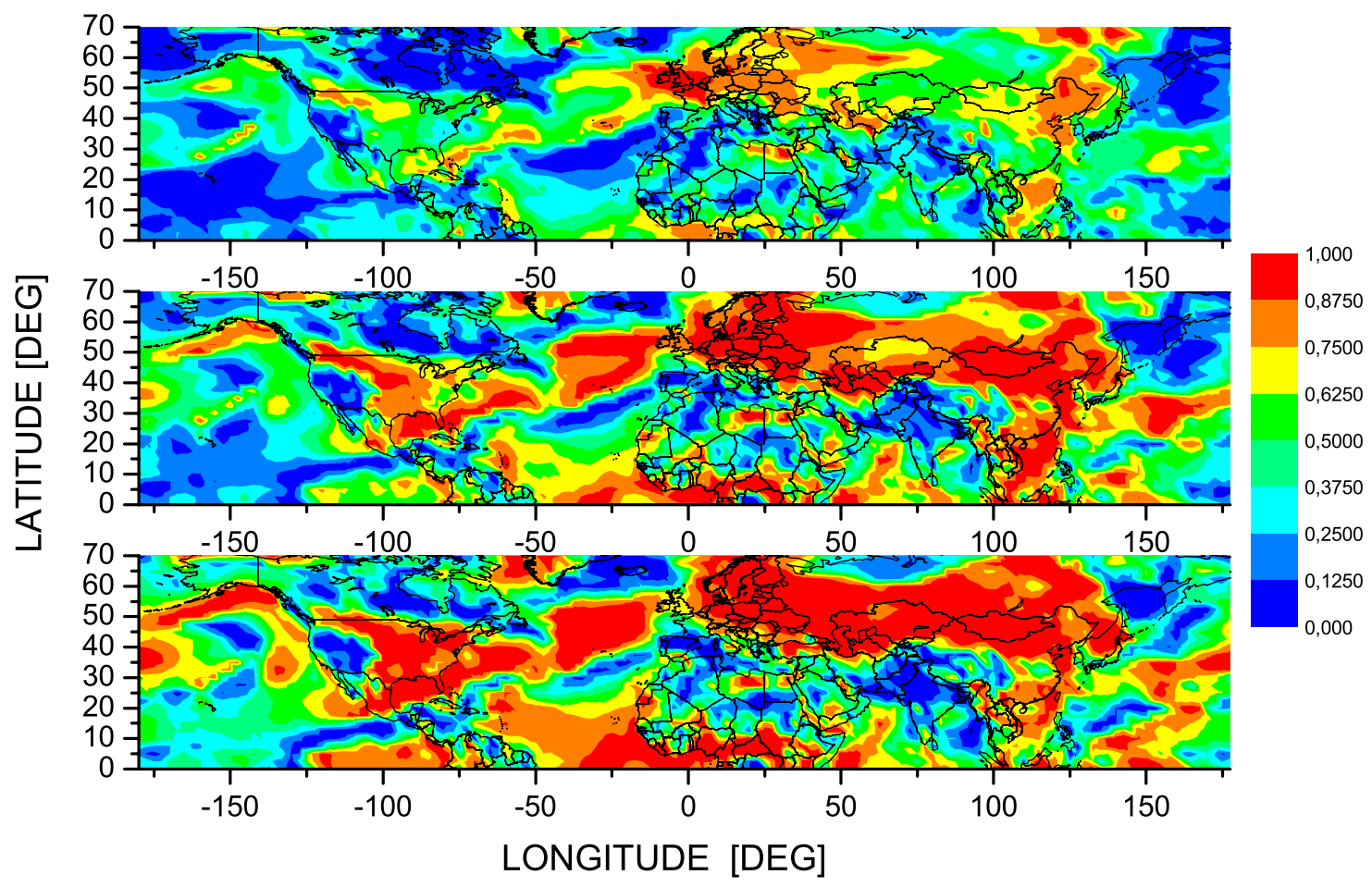

Fig. 2. The mean phase coherence between the sunspot data (top panel), geomagnetic aa index (middle panel), NAO index (bottom panel) and the ERA40 near-surface air temperature for the oscillatory modes obtained using CCWT with the central wavelet period 96 months.

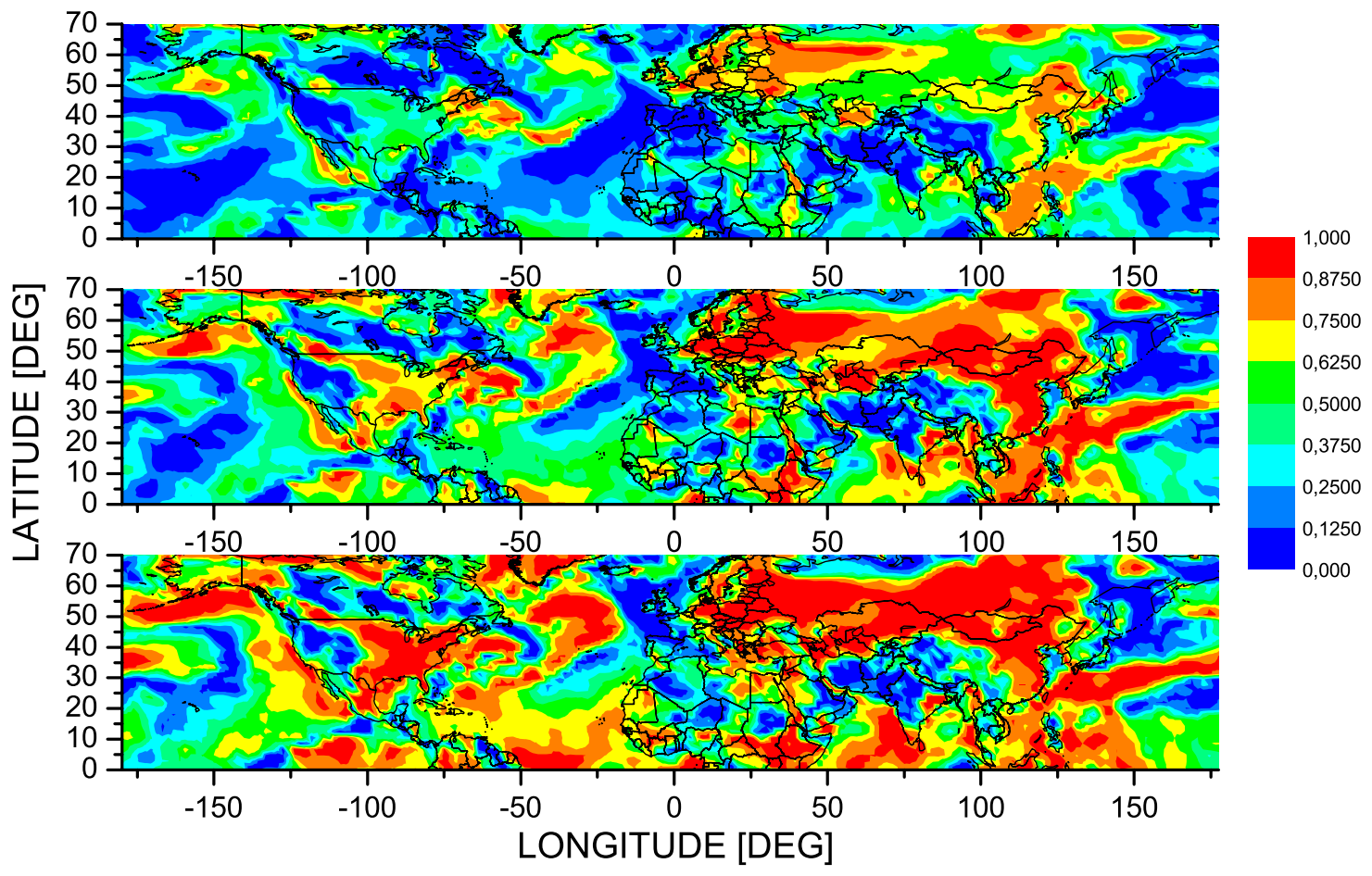

Fig. 3. The mean phase coherence between the sunspot data (top panel), geomagnetic aa index (middle panel), NAO index (bottom panel) and the NCEP/NCAR near-surface air temperature for the oscillatory modes obtained using CCWT with the central wavelet period 96 months. 


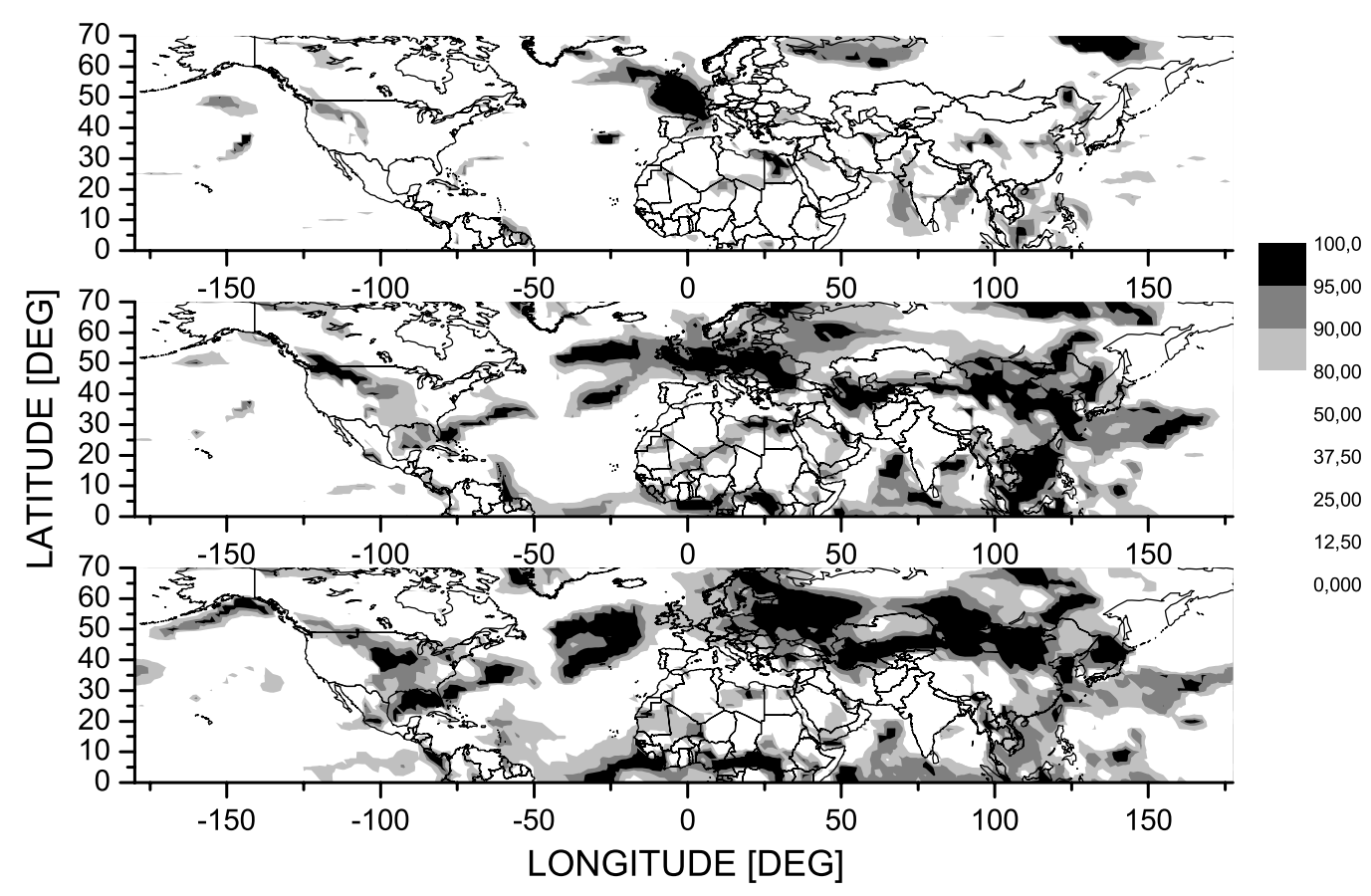

Fig. 4. The significance levels for the mean phase coherence between the sunspot data (top panel), geomagnetic aa index (middle panel), NAO index (bottom panel) and the ERA40 near-surface air temperature for the oscillatory modes obtained using CCWT with the central wavelet period 96 months. The shadowed levels are $80 \%$ ( $p<0.2$, light grey), $90 \%$ ( $p<0.1$, dark grey), and 95\% ( $p<0.05$, black).

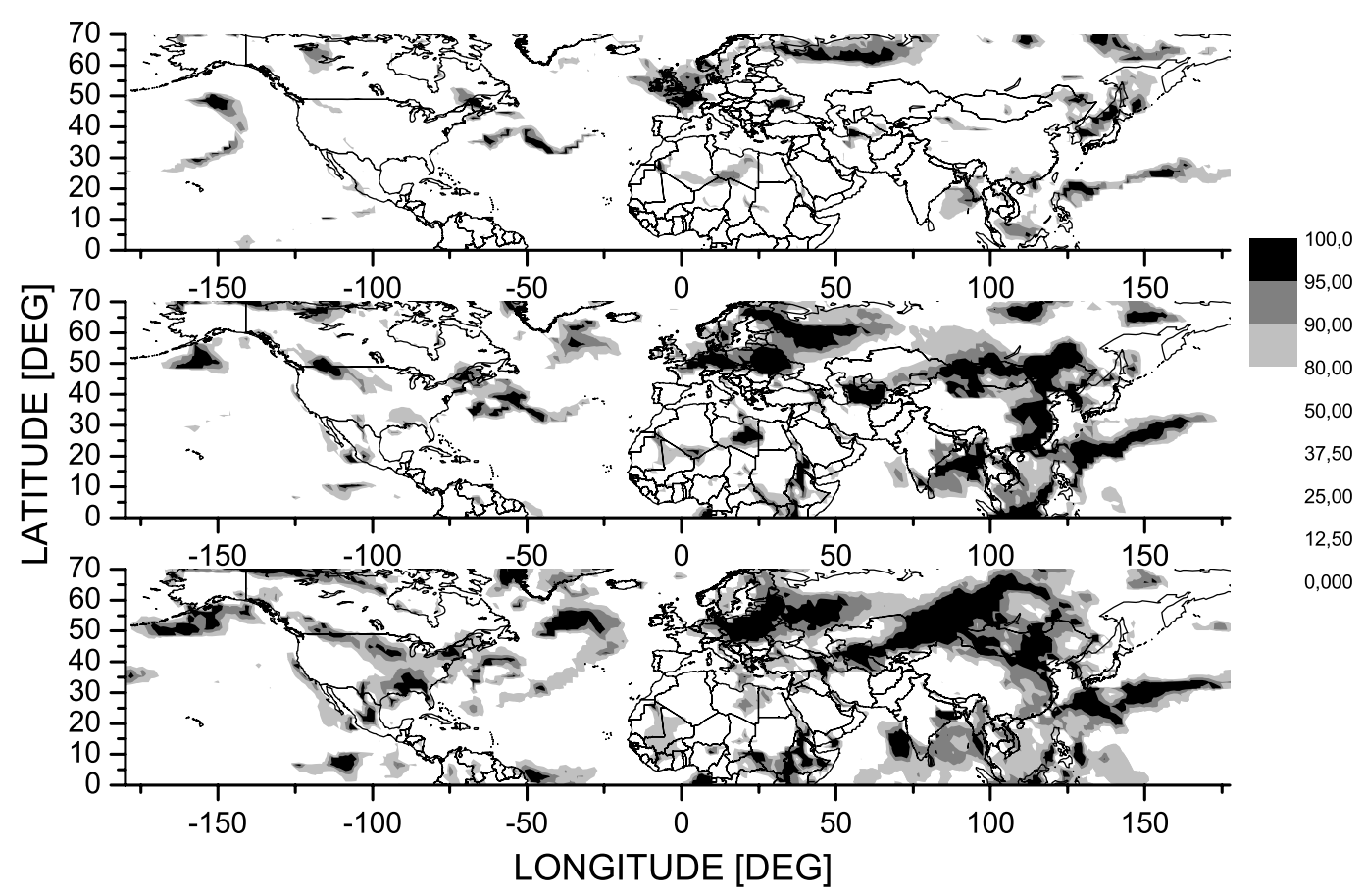

Fig. 5. The significance levels for the mean phase coherence between the sunspot data (top panel), geomagnetic aa index (middle panel), NAO index (bottom panel) and the NCEP/NCAR near-surface air temperature for the oscillatory modes obtained using CCWT with the central wavelet period 96 months. The shadowed levels are $80 \%$ ( $p<0.2$, light grey), $90 \%$ ( $p<0.1$, dark grey), and 95\% ( $p<0.05$, black). 
realistic approach would need to estimate the number of actually independent tests which is not a trivial task. Therefore we present spatially mapped significance based on single tests in Fig. 4 for the ERA40 and in Fig. 5 for the NCEP/NCAR reanalysis data, for better understanding of the absolute MPC values, rather then as a statistical evidence. We remind that we were able to perform the appropriate rigorous tests using the above mentioned station data, so that the statistical evidence for the existence of the discussed phase coherence has been presented in (Paluš and Novotná, 2009).

\section{Discussion of the results}

A quick comparison of the top and middle panels in Figs. 2-5 reminds the results from the station data (Paluš and Novotná, 2009) where the coherence of temperature with the sunspot data has been weaker than that with the geomagnetic data, however, all the results were statistically significant. Here the areas of high coherence between temperature and the sunspot data (top panels in Figs. 2-5) are less extended than the areas of high coherence between temperature and the aa index (middle panels in Figs. 2-5). The areas of high coherence of temperature with the sunspot data are subsets of the coherence areas of temperature with the aa index. This generally seems to be the case, with one exception - the Great Britain and Ireland, the areas with quite high and statistically significant phase coherence between temperature and the sunspot data, but with low (insignificant in NCEP/NCAR data) coherence with the aa index.

Since Paluš and Novotná (2009) observed mutual coherence of temperature, the sunspot data, the aa index and the NAO index, it might be useful to study also the coherence patterns between temperature and the NAO index (bottom panels in Fig. 2-5). These areas are the most extended and include consistently the areas of phase coherence of temperature with the geomagnetic aa index and consequently also the areas of coherence with the sunspot data, however, with the exception of the Great Britain and Ireland, as noted above. The area of high phase coherence of temperature with NAO corresponds to the area of impacts of Atlantic climate variability depicted by Marshall et al. (2001).

These findings could open the debate about the role of the NAO phenomenon (Hurrell et al., 2001a,b) in possible transmission of the solar signal from the stratosphere to the troposphere and about the role of geomagnetic activity in the climate variability.

\section{General discussion and conclusion}

Thejll et al. (2003) observed correlations between the geomagnetic Ap index and the winter NAO, increasing from 1950 's, although statistically significant from 1970's. Using filtered data of the yearly aa index and the winter NAO index, Lukianova and Alekseev (2004) claim that their correlation is significant since the end of 1940's. Paluš and Novotná $(2007,2008)$ proved existence of common oscillatory modes (i.e., the modes with the same average period) in the solar/geomagnetic and climate data. Therefore they were able to apply the synchronization analysis in order to find a possible dependence between the phases of the observed oscillatory modes, and thus to find possible scale-specific relationships of the solar, geomagnetic and climate variability. The phase coherence has been found and statistically confirmed in relationships of the oscillatory modes with the period of approximately 7-8 years detected in the sunspot data, the aa index, the NAO index and the near-surface air temperature from several European stations, starting in 1950's in the continuous monthly records independent of the season, and without any special preprocessing such as removal of El Niño and volcanic signals (Paluš and Novotná, 2009).

In this paper we present the Northern Hemisphere patterns of phase coherence between solar/geomagnetic activity and NCEP/NCAR and ERA40 near-surface air temperature in period 7-8 years oscillatory modes, again in the continuous monthly records independent of the season, and without any special data preprocessing. The temporal scale related to the oscillatory period 7-8 years has not been chosen arbitrarily, but based on our previous results proving the existence of the period 7-8 years oscillatory modes in the solar/geomagnetic and climate data (Paluš and Novotná, 1998, 2004, 2007, 2008).

It is important to note that our oscillatory modes detection results are not isolated in the scientific literature. Plaut et al. (1995) detected an oscillatory component with the period 7.7 years in 335 years long central England temperature record. The oscillatory mode with the period of 7.8 years has been detected in the NAO, in the Arctic Oscillation, in the Uppsala winter near-surface air temperature, as well as in the Baltic Sea ice annual maximum extent by Jevrejeva and Moore (2001). Applying MCSSA to the winter NAO index, Gámiz-Fortis et al. (2002) detected oscillations with the period 7.7 years. Unal and Ghil (1995) and Jevrejeva et al. (2006) observed oscillations with periods of 7-8.5 years in a number of sea level records. Feliks and Ghil (2007) report the significant oscillatory mode with the 7.8 year period in the Nile River record, the Jerusalem precipitation, tree rings and in the NAO index. Da Costa and Colin de Verdiere (2002) have detected oscillations with the period 7.7 years in interactions of the sea surface temperature and the sea level pressure. Using global sea-surface temperature fields, Moron et al. (1998) observed 7-8 years oscillations involving the entire double-gyre circulation of the North Atlantic. In an analysis of the mechanisms responsible for interannual variability in the Greenland Iceland-Norwegian Seas, Gámiz-Fortis and Sutton (2007) obtained a quasi-periodic, similar to 7year signal in sea surface temperature and sea surface salinity using a control integration of the HadCM3 coupled climate model. Thus the oscillatory phenomena with the period 
7-8 years present an important part of climate variability. We have shown the Northern Hemisphere patterns of phase coherence between the period 7-8 years oscillatory modes in near-surface air temperature and solar/geomagnetic activity during the second half of the 20th century.

Tung and Camp (2008) discussed some inconsistency between the ERA40 and NCEP/NCAR reanalysis data related to derivation of the surface temperature. Gleisner et al. (2005) reported weaker solar signal response in the ERA40 data than in the NCEP/NCAR data in the upper troposphere thickness, and substantially weaker solar signal response in both data sets in lower troposphere thickness. Pišoft et al. (2009) point to inconsistencies in occurrence of approximate 8 years periodicities in different geopotential levels in reanalysis temperature data with weaker signal in the ERA40 data set. Using the temporal scale of naturally existing oscillatory phenomena we have found almost consistent results using both the ERA40 and NCEP/NCAR reanalysis data. We pose a question about a possible role of the NAO in the transmission of the solar influence from the stratosphere to the troposphere. The future aims range from technical tasks (analysis of different solar data, inclusion of the Southern Hemisphere), through theoretical challenges related to the origin of the observed oscillatory modes and their interactions (Does NAO play a role in the solar signal transition mechanism from the stratosphere to the troposphere? Or, is NAO the instigator of the observed phase coherence and other synchronization phenomena which can lead to climate shifts, as recently proposed by Wang et al. (2009)?) to the quite critical question about the role of this part of climate variability in the present climate change.

The atmospheric processes are nonlinear and thus we cannot expect full understanding of weather and climate evolution within the framework of linear theory. Nonlinear phenomena such as phase synchronization can help to understand cooperative behaviour and coupling within atmospheric phenomena and with possible external influences. We believe that the presented results will foster relevant discussions and the research in this direction can contribute to understanding of the role of the solar and geomagnetic activity in the changing climate.

Acknowledgements. This study was supported by the Grant Agency of the Academy of Sciences of the Czech Republic project No. IAA300420805, and in part by the Institutional Research Plans AV0Z10300504 and AV0Z30420517.

Edited by: J. Kurths

Reviewed by: two anonymous referees

\section{References}

Camp, Ch. D. and Tung, K. K.: Surface warming by the solar cycle as revealed by the composite mean difference projection, Geophys. Res. Lett., 34, L14703, doi:10.1029/2007GL030207, 2007.

Da Costa, E. D. and de Verdiere, A. C.: The 7.7-year North Atlantic Oscillation, Q. J. R. Meteorol. Soc., 128, 797-817, 2002.

De Jager, C.: Solar forcing of climate. 1: Solar variability, Space Sci. Rev., 120, 197-241, 2005.

De Jager, C. and Usoskin, I. G.: On possible drivers of Suninduced climate changes, J. Atmos. Sol.-Terr. Phys., 68, 20532060, 2006.

Feliks, Y. and Ghil, M.: Interannual, synchronized oscillations over the North Atlantic, Eastern Mediterranean and Ethiopian Plateau, Geophys. Res. Abstr., 9, 05600, 2007.

Gabor, D.: Theory of Communication, J. IEE London, 93(3), 429457, 1946.

Gámiz-Fortis, S. R., Pozo-Vázques, D., Esteban-Parra, M. J., and Castro-Díez, Y.: Spectral characteristics and predictability of the NAO assessed through Singular Spectral Analysis, J. Geophys. Res., 107(D23), 4685, doi:10.1029/2001JD001436, 2002.

Gámiz-Fortis, S. R. and Sutton, R. T.: Quasi-periodic fluctuations in the Greenland-Iceland-Norwegian Seas region in a coupled climate model, Ocean Dyn., 57(6), 541-557, 2007.

Gleisner, H. and Thejll, P.: Patterns of tropospheric response to solar variability, Geophys. Res. Lett., 30(13), 1711, doi:10.1029/2003GL017129, 2003.

Gleisner, H., Thejll, P., Stendel, M., Kaas, E., and Machenhauer, B.: Solar signals in tropospheric re-analysis data: Comparing NCEP/NCAR and ERA40, J. Atmos. Sol.-Terr. Phys., 67, 785$791,2005$.

Haigh, J. D.: The effects of solar variability on the Earth's climate, Phil. Trans. R. Soc. Lond. A, 361, 95-111, 2003.

Haigh, J. D.: Solar variability and climate, Astrophys. Space Sc. L., 344, 65-81, 2005.

Haigh, J. D.: The Sun and Earth's Climate, Living Rev. Solar Phys., 4, lrsp-2007-2, http://solarphysics.livingreviews.org/ Articles/lrsp-2007-2/, last access: 30 March 2011, 2007.

Hurrell, J. W., Kushnir, Y., and Visbeck, M.: The North Atlantic Oscillation, Science, 291(5504), 603-605, 2001a.

Hurrell, J. W., Kushnir, Y., Ottersen, G., and Visbeck, M.: Climate - An Overview of the North Atlantic Oscillation, The North Atlantic Oscillation, Geophys. Monograph, 134, 1-33, $2001 \mathrm{~b}$.

Jevrejeva, S. and Moore, J. C.: Singular Spectrum Analysis of Baltic Sea ice conditions and large-scale atmospheric patterns since 1708, Geophys. Res. Lett., 28(23), 4503-4506, 2001.

Jevrejeva, S., Grinsted, A., Moore, J. C., and Holgate, S.: Nonlinear trends and multiyear cycles in sea level records, J. Geophys. Res., 111, C09012, doi:10.1029/2005JC003229, 2006.

Kalnay, E., Kanamitsu, M., Kistler, R., Collins, W., Deaven, D., Gandin, L., Iredell, M., Saha, S., White, G., Woollen, J., Zhu, Y., Chelliah, M., Ebisuzaki, W., Higgins, W., Janowiak, J., Mo, K., Ropelewski, C., Wang, J., Leetmaa, A., Reynolds, R., Jenne, R., and Joseph, D.: The NCEP/ NCAR 40-year re-analysis project, Bull. Am. Meteorol. Soc., 77, 437-471, 1996.

Klein-Tank, A. M. G., Wijngaard, J. B., Können, G. P., Böhm, R., Demarée, G., Gocheva, A., Mileta, M., Pashiardis, S., Hejkrlik, L., Kern-Hansen, C., Heino, R., Bessemoulin, P., MüllerWestermeier, G., Tzanakou, M., Szalai, S., Pálsdóttir, T., Fitzgerald, D., Rubin, S., Capaldo, M., Maugeri, M., Leitass, A., Bukan- 
tis, A., Aberfeld, R., van Engelen, A. F. V., Forland, E., Mietus, M., Coelho, F., Mares, C., Razuvaev, V., Nieplova, E., Cegnar, T., López, J. A., Dahlström, B., Moberg, A., Kirchhofer, W., Ceylan, A., Pachaliuk, O., Alexander, L. V., and Petrovic, P.: Daily dataset of 20th century surface air temperature and precipitation series for the European Climate Assessment, Int. J. Climatology, 22, 1441-1453, 2002.

Lean, J., Wang, Y. M., and Sheeley, N. R.: SORCE contribution to new understanding of global change and solar variability, Sol. Phys., 230, 27-53, 2005.

Lean, J. L. and Rind, D. H.: How natural and anthropogenic influences alter global and regional surface temperatures: 1889 to 2006, Geophys. Res. Lett., 35, L18701, doi:10.1029/2008GL034864, 2008.

Lockwood, M.: Recent changes in solar outputs and the global mean surface temperature. III. Analysis of contributions to global mean air surface temperature rise, Proc. R. Soc. A, 464, 13871404, 2009.

Lockwood, M. and Frohlich, C.: Recent oppositely-directed trends in solar climate forcing and the global mean surface air temperature, Proc. R. Soc. A, 463, 2447-2460, 2007.

Lu, H., Jarvis, M. J., Graf, H.-F., Young, P. C., and Horne, R. B.: Atmospheric temperature response to solar irradiance and geomagnetic activity, J. Geophys. Res., 112, D11109, doi:10.1029/2006JD007864, 2007.

Lukianova, R. and Alekseev, G.: Long-term correlation between the NAO and solar activity, Solar Phys., 224, 445-454, 2004.

Maraun, D. and Kurths, J.: Epochs of phase coherence between El Niño/Southern Oscillation and Indian monsoon, Geophys. Res. Lett., 32(15), L15709, doi:10.1029/2005GL023225, 2005.

Marshall, J., Kushnir, Y., Battist, D., Chang, P., Czaja, A., Dickson, R., Hurrel, J., McCartney, M., Saravanan, R., and Visbeck, M.: North Atlantic climate variability: Phenomena, Impacts and Mechanisms, Int. J. Climatol., 21, 1863-1898, 2001.

Mayaud, P. N.: The aa indices: a 100year series characterizing the magnetic activity, J. Geophys. Res., 77(34), 6870-6874, 1972.

Mokhov, I. I. and Smirnov, D. A.: El Niño-Southern Oscillation drives North Atlantic Oscillation as revealed with nonlinear techniques from climatic indices, Geophys. Res. Lett., 33(3), L03708, doi:10.1029/2005GL024557, 2006.

Moore, J., Grinsted, A., and Jevrejeva, S.: Is there evidence for sunspot forcing of climate at multi-year and decadal periods? Gephys. Res. Lett., 33, L17705, doi:10.1029/2006GL026501, 2006.

Moron, V., Vautard, R., and Ghil, M.: Trends, interdecadal and interannual oscillations in global sea-surface temperatures, Clim. Dynam., 14(7-8), 545-569, 1998.

Paluš, M.: Detecting phase synchronization in noisy systems, Phys. Lett. A, 235, 341-351, 1997.

Paluš, M.: From Nonlinearity to Causality: Statistical testing and inference of physical mechanisms underlying complex dynamics, Contemp. Phys., 48(6), 307-348, 2007.

Paluš, M. and Novotná, D.: Detecting modes with nontrivial dynamics embedded in colored noise: Enhanced Monte Carlo SSA and the case of climate oscillations, Phys. Lett. A, 248, 191-202 1998.

Paluš, M. and Novotná, D.: Enhanced Monte Carlo Singular System Analysis and detection of period 7.8 years oscillatory modes in the monthly NAO index and temperature records, Nonlin. Pro- cesses Geophys., 11, 721-729, doi:10.5194/npg-11-721-2004, 2004.

Paluš, M. and Novotná, D.: Quasi-biennial oscillations extracted from the monthly NAO index and temperature records are phase-synchronized, Nonlin. Processes Geophys., 13, 287-296, doi:10.5194/npg-13-287-2006, 2006.

Paluš, M. and Novotná, D.: Common oscillatory modes in geomagnetic activity, NAO index and surface air temperature records, J. Atmos. Sol.-Terr. Phys., 69, 2405-2415, 2007.

Paluš, M. and Novotná, D.: Detecting Oscillations Hidden in Noise: Common Cycles in Atmospheric, Geomagnetic and Solar Data, in: Nonlinear Time Series Analysis in the Geosciences - Applications in Climatology, Geodynamics, and Solar-Terrestrial Physics. Lecture Notes in Earth Sciences, edited by: Donner, R. and Barbosa, S., 112, Springer, Berlin, 327-354, 2008.

Paluš, M. and Novotná, D.: Phase-coherent oscillatory modes in solar and geomagnetic activity and climate variability, J. Atmos. Sol.-Terr. Phys., 71, 923-930, 2009.

Paluš, M., Kurths, J., Schwarz, U., Novotná, D., and Charvátová, I.: Is the solar activity cycle synchronized with the solar inertial motion?, Int. J. Bif. Chaos, 10, 2519-2526, 2000.

Paluš, M., Novotná, D. and Tichavský, P.: Shifts of seasons at the European mid-latitudes: Natural fluctuations correlated with the North Atlantic Oscillation, Geophys. Res. Lett., 32, L12805, doi:10.1029/2005GL022838, 2005.

Paluš, M., Kurths, J., Schwarz, U., Seehafer, N., Novotná, D., and Charvátová, I.: The solar activity cycle is weakly synchronized with the solar inertial motion, Phys. Lett. A, 365, 412-428, 2007.

Pikovsky, A., Rosenblum, M., and Kurths, J.: Synchronization. A Universal Concept in Nonlinear Sciences, Cambridge University Press, Cambridge, 2001.

Pišoft, P., Mikšovský, J., and Žák, M.: An analysis of the spatial distribution of approximate 8 years periodicity in NCEP/NCAR and ERA-40 temperature fields, Eur. Phys. J. Special Topics, 174, 147-155, 2009.

Plaut, G., Ghil, M., and Vautard, R.: Interannual nad interdecadal variability in 335 years of central England temperatures, Science, 268, 710-713, 1995.

Rind, D., Lean, J., Lerner, J., Lonergan, P., and Leboissitier, A.: Exploring the stratospheric/tropospheric response to solar forcing, J. Geophys. Res.-A, 113, D24103, doi:10.1029/2008JD010114, 2008.

Rosenblum, M. G., Pikovsky, A. S., and Kurths, J.: Phase synchronization of chaotic oscillators, Phys. Rev. Lett., 76, 1804-1807, 1996.

Salby, M. L. and Callaghan, P. F.: Relationship of the quasibiennial oscillation to the stratospheric signature of the solar cycle, J. Geophys. Res., 111, D06110, doi:10.1029/2005JD006012, 2006.

Schäfer, C., Rosenblum, M. G., Kurths, J., and Abel, H.-H.: Heartbeat synchronized with ventilation, Nature, 392, 239, doi:10.1038/32567, 1998.

Simmons, A. J. and Gibson, J. K.: The ECMWF Project Plan, ECMWF Project Report Series, 1, ECMWF, Reading, UK, 2000.

Simpson, I. R., Blackburn, M., and Haigh, J. D.: The role of eddies in driving the tropospheric response to stratospheric heating perturbations, J. Atmos. Sci., 66(5), 1347-1365, 2009.

Tatli, H.: Synchronization between the North Sea-Caspian pattern (NCP) and surface air temperatures in NCEP, Int. J. Climatol. 
27, 1171-1187, 2007.

Thejll, P., Christiansen, B., and Gleisner, H.: On correlation between the North Atlantic Oscillation, geopotential heights, and geomagnetic activity, Geophys. Res. Lett., 30(6), 1347, doi:10.1029/2002GL016598, 2003.

Tinsley, B. A.: The global atmospheric electric circuit and its effects on cloud microphysics, Rep. Prog. Phys., 71, 066801, doi:10.1088/0034-4885/71/6/066801, 2008.

Torrence, C. and Compo, G. P.: A practical guide to wavelet analysis, Bull. Am. Meteorol. Soc., 79(1), 61-78, 1998.

Tung, K. K. and Camp, Ch. D.: Solar cycle warming at the Earth surface in NCEP and ERA40 data: A linear diskriminant analysis, J. Geophys. Res., 113, D05114, doi:10.1029/2007JD009164, 2008.
Unal, Y. S. and Ghil, M.: Interannual and interdecadal oscillation patterns in sea level, Clim. Dynam., 11, 255-278, 1995.

Usoskin, I. G., Schussler, M., Solanki, S. K., and Mursula, K.: Solar activity, cosmic rays, and Earth's temperature. A millenium-scale comparison, J. Geophys. Res., 110, A10102, doi:10.1029/2004JA010946, 2005.

Wang, G., Swanson, K. L., and Tsonis, A. A.: The pacemaker of major climate shifts, Geophys. Res. Lett., 36, L07708, doi:10.1029/2008GL036874, 2009. 